\title{
Impact of gamification and experiential learning on achievement in mathematics among learners with hearing impairment in Lagos State, Nigeria
}

\author{
S. O. Adeniyi ${ }^{1} \&$ O. O. Kuku ${ }^{2}$
}

\begin{abstract}
There had been mixed observations about the ability and achievement of learners with hearing impairment. However, there are consensus that impactful teaching effort could aid in stimulating innovative approaches in teaching and learning of mathematics of learners particularly among learners with hearing impairment. This study seeks to appraise the impact of gamification and experiential learning on achievement in mathematics among learners with hearing impairment in Lagos State, Nigeria. The study population comprised learners with hearing impairment in Lagos State. Purposive and simple random sampling were used to select sample of 24 learners. The research design used was quasi-experimental pretest posttest traditional method group. Mathematics Knowledge Check (MKC) was used to collect data and the data collected were analyzed using mean, standard deviation, mean difference and analysis of covariance (ANCOVA). The hypotheses were tested at 0.05 level of significance. The study found out that achievement in Mathematics differs as a result of exposing learners with hearing impairment to gamification and experiential learning methods of instruction. Besides, the study observed that the two interventions benefit were of benefit to male and female learners with hearing impairment. The employment of gamification and experiential learning instructional strategy was recommended for mathematics lessons of learners with hearing impairment.
\end{abstract}

Keywords: gamification, experiential learning, achievement in mathematics, learners with hearing impairment

\section{Introduction}

The knowledge of mathematics is a necessary and valuable life skill which is applicable for numerous human activities and profession. This may be one the reasons why mathematics is included and made one of the compulsory subjects in primary and secondary schools in Nigeria. However, the process of learning mathematics can affect learners (either with or without disabilities) differently. A number of researchers found that learner with hearing impairment are academically behind their hearing peers and mathematics is one of the subjects that they find challenging (Adeniyi \& Kuku, 2018; Ashmore, 2017; Sylvia, 2015). Though, mathematics has been observed as a subject where learners' achievement has been quite poor (Kuku, 2019), but communication

\footnotetext{
${ }^{1}$ Samuel Olufemi Adeniyi, Department of Educational Foundations, University of Lagos, Nigeria. Email: soadeniyi@unilag.edu.ng

${ }^{2}$ Olaotan Oladele Kuku, Department of Educational Psychology, Federal College of Education (Technical), Akoka, Lagos State, Nigeria. Email: olaotan.kuku@yahoo.com
}

Open Access article distributed under the terms of the Creative Commons Attributions License [CC BY-NC-ND 4.0] http://creativecommons.org/licenses/by-nc-nd/4.0. DOI: https://dx.doi.org/10.4314/ajesms.v16i.2.4 
Impact of gamification and experiential learning on achievement in mathematics among learners with hearing impairment in Lagos State, Nigeria

S. O. Adeniyi $i^{1} \&$ O. O. Kuku ${ }^{2}$

challenges may have added to the poor achievement of learners with hearing impairment. Ashmore (2017) submits that language barrier may have added to learners with hearing impairment inability to comprehend mathematical concepts among middle and high school learners.

However, several other researchers' submissions varied from the view that hearing loss is a major cause of low achievement in mathematics. Other studies like Caemmerer, Cawthon and Bond (2016) held the view that about $50 \%$ of learners with hearing impairment possesses a cooccurring disability and that some professionals may not hesitate to diagnose other disabilities in a learner with hearing impairment because of the difficulty in ruling out the student's hearing loss and reduced exposure to language and communication models as a primary cause of a disability. Nevertheless, Nunes and Moreno (1998) ruled out the possibility of co-occurring disabilities and took a position of indifference in the cognitive abilities between learners with and without hearing loss (as cited in Ashmore, 2017).

Learners with hearing impairment are group of learners among the special needs children whom have been observed to have declining achievement in mathematics because of the complexity of some associated problem aside hearing loss. According to Ashmore (2017), learners with hearing impairment have severe hearing loss that ranges from hard of hearing to profound loss. In classroom environment, the indicator of learners' success is the academic achievement. This refers to the level of proficiency attained in a particular academic exercise. Arora (2016) defined academic achievement as the knowledge attained and skills developed during their academic career which is assessed by school authorities with the help of teacher-made or standardized tests. It is one of the most important goals of education and a major criterion for selection, promotion, evaluation and certification particularly in the education system. Very unfortunately, academic achievement of students with hearing impairment in the past and recent times have been on the downward trend because of the peculiarity of hearing loss and some other intervening factors

Hearing is an essential part of learning, playing, interaction and developing social skills. Any level of hearing loss can negatively affect development and learning in school. Despite the several options open to learners with hearing impairment which include special schools, regular schools with special education classes, or regular schools with regular and inclusive classroom for them to improve on their academic achievement, learning mathematics had been documented to be difficult for students with hearing impairment (Adeniyi \& Kuku, 2018; Shelton \& Parlin, 2016; Tanridiler, Uzuner \& Girgin, 2015; Nunes \& Moreno 2002). The reasons for this have been identified not only predicated on hearing loss and language difficulty but also, instructional approach during teaching and learning process (Shelton \& Parlin, 2016; Sylvia, 2015; National Council of Teachers of Mathematics, 2010).

Tanridiler, Uzuner and Girgin (2015) reported that learners with hearing impairment can learn mathematics just as their hearing peers but at a delayed pace. However, Pagliaro and Kritzer (2005) attributed the low achievement of learners with hearing impairment to heavy reliance on traditional practice of rote learning and procedural understanding with little emphasis on higher order thinking and true problem solving. The gap in achievement in 
African Journal of Educational Studies in Mathematics and Sciences Vol. 16, No. 2, 2020

mathematics among this group has been attributed to improper use of instructional materials as well as weakness in teaching (Noorian, Maleki, \& Abolhassani, 2013). Thus, the National Council of Teachers of Mathematics (2000) submits that achievement among learners with hearing impairment can be improved through instructional approaches that can engage them in challenging mathematics problems. A number of researches had been conducted on learners with hearing impairment to determine the impact of several interventions on the level of achievement in mathematics. The outcomes have yielded little progress. It is on this note that this study employed gamification and experiential learning approaches to improve achievement in mathematics among learners with hearing impairment

Gamification in teaching and learning process is a relatively new concept. Gamification is considered a new methodology that represents a new pedagogical model for 21st-century educators (Taspinar, Schmidt, \& Schuhbauer, 2016). It is defined as the use of game mechanics in traditionally nongame activities. In an educational setting, gamification is used to introduce game mechanics into learning components and learning activities, thus transforming traditional learning exercises into actionoriented and interactive activities (Jagoda, 2013).Game play has been reported as having considerable potential for developing various skills and abilities such as visualization, spatial and navigational abilities, reaction times, reflexes, psychomotor skills, and multitasking, as well as hand-eye coordination and higher order cognitive skills that include critical and strategic thinking, analytical skills, and critical reasoning ((Boyle, Hainey, Connolly, Gray, Earp, Ott, et al., 2016;
Hainey, Connolly, Azadegan, Amanda \& Gray, 2014).

Appiah (2015) during the study of gamification in improving elementary mathematics in Kumasi, Ghana reported that the introduction of gamification encouraged active participatory and collaborative learning by engaging learners in the study of mathematics. In addition, a change was observed in the classroom dynamics and fostered new teaching and learning approaches which boosted learners-teacher interactivity, this made learners active and increase their engagement in learning mathematics. In related study, Marinagi and Skourlas (2013) used a developed webbased game activity that integrates wireless networks and mobile devices into educational scenarios. It was observed that there was increase interest in daily studies and improves communications between learners and teachers. Also, in a study by Gafni, Achituv, Eidelman and Chatsky (2018) on the effects of gamification elements in e-learning platforms revealed that students exposed to gamified e-learning platforms demonstrated high achievement in learning and were motivated to continue learning after the experience. These outcomes lend credence to the efficacy of game in learning process.

The introduction of interventions had been observed to have gender implication. Study on the effectiveness of two instructional methods on reasoning ability of elementary school children with hearing impairment in Lagos State, Nigeria by Adeniyi and Kuku (2018) reported no significant difference in the reasoning ability of male and female children with hearing impairment. However, Appiah (2015) carried out a study on the use of gamification strategy to improve mathematics among elementary school pupils with samples of 114 male pupils and 116 female pupils using purposive sampling 
Impact of gamification and experiential learning on achievement in mathematics among learners with hearing impairment in Lagos State, Nigeria

S. O. Adeniyi $i^{1} \&$ O. O. Kuku ${ }^{2}$

technique. The result revealed that both male and female participants befitted equally from the learning strategy. This is to show that the instructional strategy will be of immense benefit to all learners not minding gender disparity. Besides, Parvez, et al. (2019) while studying the effectiveness of Mobile Application in Learning Basic Mathematical concepts using sign language reported a better performance in male participants above their female counterparts.

On the other hands, experiential learning is another instructional strategy that anchors on the fact that learning is at its best when learners are allowed to discover learning contents by interacting, reflecting and critical analyses of contents to be learnt. In this wise, when experiences are meticulously chosen and interacted with during classroom instruction, it possibly aids reflection, critical analysis and synthesis. Such experiences can provoke learners' initiative, make informed decision, making learners assume responsibility and being accountable for results. Thus, Experiential learning is an approach to learning that is holistic and integrative in nature that combines experience, perception, cognition, and behavior (Lester, 2007). Experiential learning theorist believed that learning should be an application of knowledge that aids the conceptual understanding of the real-world problems or situation. The theory posited that experiential learning is the process whereby knowledge is created through the combination of grasping and transformation of experience (Kolb, 1984, as cited in Nath, 2016). Experiential learning complements students' academic learning and provides youth with experiences and knowledge that maximize their growth and development while meeting their needs for career exploration (Canadian Council on Learning, 2009). Kolb in (McGill \& Beaty,
1995) proposed four-stage experiential learning model which he believed is continuous and cyclical. These are: concrete experience, reflective observation, abstract conceptualization and active experimentation. Kolb noted that there is no limit to the number of cycle one can make in a learning situation. So, the cycle is continuous until mastery is achieved.

Seaman and Rheingold (2013) pointed out that experiential learning is always a social accomplishment that is rooted through particular practices and social collaboration, thus, allowing the learner to make sense of content through a personal lens. The incorporation of social interactions and fellowship encourages students to have open discourse which allows them to express their ideas regardless of whether their ideas are reflective of concrete situations or more abstract in nature. Mathematics, especially algebra, requires students to be able to comprehend and manipulate material presented in abstract form, so there is great possibility for improvement by using experiential learning methods. Hence, interventions organized around the experiential learning theory may show promise for impacting student achievement in mathematics and for enriching their lives in a broader sense by yielding access to the more advanced material necessary for accomplishing goals in a highly technologically advanced society. In an education reform carried out in between 2010-2011 on how to increase academic standard and improve secondary school success for all students by $85 \%$ in Ontario, experiential learning approach was employed. The outcome of the reforms have led to important changes in the secondary school system, such as the creation of Specialist High Skills Majors and expanded cooperative education, providing students 
with valuable experiential learning opportunities that help prepare them for life after high school. Therefore, experiential learning complements students' academic learning and provides youth with experiences and knowledge that maximize their growth and development while meeting their needs for career exploration (Canadian Council on E-learning, 2011). Also, in a study by Nath (2016) on instructional programme on experiential learning in science education, the outcome of the study revealed that motivation is of interest in learning among participants. The impact of experiential learning on this psychological construct is an indication that such strategy will also influence positive change in cognitive domain.

Türkmen and Soybaş (2019) reported the role of gamification in motivating and helps in internalizing the external motivation provided by game components which aids active learning and promotes competition, entertainment and excitement offered by the games. Learning is seen as an activity-based teaching approach that enable the learners explore relationships between concepts learnt in science which gives room for the use of the learners to prior knowledge, experiences and self-motivation to acquire new knowledge (Wynn, 2018; Nath, 2016). While experiential learning is an active learning that is characterized by studentcentered activities, Banfield and Wilkerson (2014) compared gamification as an offshoot of experiential learning that uses the combination of game components which include score, challenge, and achievement with learning objectives aimed at engaging and motivating the learners.

From the foregoing, it is evident that both gamification and experiential learning strategies have proved to be impactful of learning and achievement of students without hearing impairment. Hence, it is necessary to test the efficacy of these instructional strategies on learning process of students with hearing impairment. Therefore, this study is on impact of gamification and experiential learning strategies on achievement in mathematics among students with hearing impairment in Lagos State, Nigeria.

\section{Research Questions}

These questions were provided answers.

1. How does achievement in mathematics differ among participants exposed to gamification and experiential learning (experiential groups) and those who were not (traditional method or control group)?

2. To what extent does achievement in mathematics differ among male and female participants exposed to the experimental conditions?

\section{Research Hypotheses}

The following hypotheses were tested at 0.05 level of significance.

1. Achievement in Mathematics will not significantly differ among participants exposed to gamification, experiential learning and traditional method group.

2. There is no significant difference in achievement in mathematics as a result exposing participants to the experimental conditions due to gender.

\section{Methodology}

A quasi-experimental, pretest posttest control group research design was used for the study. The design was adopted because the experiment involved human that cannot be subjected to full randomization. The 
Impact of gamification and experiential learning on achievement in mathematics among learners with hearing impairment in Lagos State, Nigeria

S. O. Adeniyi $i^{1} \&$ O. O. Kuku ${ }^{2}$

population of the study comprised all hearing-impaired learners in Lagos Metropolis. Simple random sampling was used to select three inclusive secondary schools out of the 31 inclusive secondary schools. In order to deliberately choose learners with hearing impairment among the learners in the inclusive schools, purposive sampling was used to select an intact class of learners in the senior secondary school among the three schools earlier selected. Table 1 show the distribution of the participants in the three Selected Schools for the study.

The sampling process led to the selection of eight participants in School A, seven participants in School B and nine participants in School C. This led to a total of 24 participants comprising 10 male and 14 females selected for the study.

An instrument titled Mathematics Knowledge Check (MKC) was used to collect relevant data. The MKC was drawn from topics meant for first term, 2019/2020 academic session of Lagos State Ministry of
Table 1 Breakdown of the Participants in the three Selected Schools

Education Scheme of Work booklet. The topics of focus and their distribution across the domains of learning (i.e., the test blueprint) is presented in Table 2 .

As will be seen in Table 2, the MKC consist of 40 multiple choice items. The Test Blueprint was used to ensure content validity of the MKC. Before the commencement of the main study, a pilot study was conducted in a school that was not part of the main study. The pilot study involving 10 learners with hearing impairment was conducted in an inclusive school that is not part of the

\begin{tabular}{clccc}
\hline & & \multicolumn{2}{c}{ Gender } & \\
\cline { 3 - 4 } School & \multicolumn{1}{c}{ Group } & Male & Female & Total \\
\hline A & Gamification & 4 & 4 & 8 \\
B & Experiential & 3 & 4 & 7 \\
C & Traditional method & 3 & 6 & 9 \\
Total & & 10 & 14 & 24 \\
\hline
\end{tabular}

main study and located in an area far enough to avoid experimental contamination. The pilot study was conducted to do a trail test of the MKC and a tryout of the administration procedure. A split half reliability which yielded a reliability coefficient of 0.79 was

Table 2 Test Blueprint for Mathematics Knowledge Check (MKC)

\begin{tabular}{|c|c|c|c|c|c|c|c|c|}
\hline Topics & $\begin{array}{l}\overrightarrow{{ }_{0}} \\
\overrightarrow{0.0} \\
\overrightarrow{3}\end{array}$ & $\begin{array}{l}0 \\
\frac{8}{0} \\
\frac{0}{3} \\
0 \\
0 \\
\pm \\
\end{array}$ & 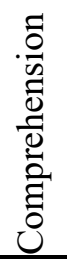 & 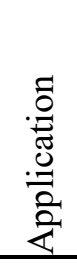 & 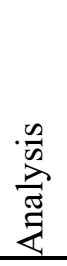 & 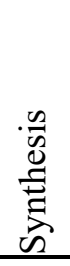 & 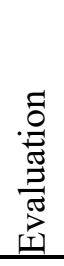 & $\begin{array}{l}\bar{\pi} \\
\stackrel{0}{0} \\
\end{array}$ \\
\hline Basic Operation & 15 & 1 & 2 & 2 & 1 & & & 6 \\
\hline Factorization & 18 & 1 & 3 & 2 & 1 & & & 7 \\
\hline Algebra & 20 & 1 & 2 & 3 & 2 & & & 8 \\
\hline Set Theory & 18 & 1 & 1 & 3 & 1 & 1 & & 7 \\
\hline Measure of Central Tendency & 30 & 1 & 3 & 3 & 3 & 1 & 1 & 12 \\
\hline Total & 100 & 5 & 11 & 13 & 8 & 2 & 1 & 40 \\
\hline
\end{tabular}


used to determine the internal consistency of MKC.

The data collection procedure took nine weeks. The instruments were administered on the participants with the help of three research assistants. The research assistants were special education teachers that studied mathematics and are skillful in sign language. They possess a minimum qualification of Nigerian Certificate in Education (NCE) with at least four years of teaching experience. These teachers were adequately trained on research ethics and were briefed with the essence of the study. The administration procedure took three stages. The initial stage started after the random selection of three schools with special needs. After the purposive sampling of learners with hearing impairment, a baseline assessment was conducted to ensure that the participants possess similar features before the commencement of the experiment. The baseline assessment was aimed at determining the level of achievement the participants in the three groups had about the topics to be used during the treatment. Thus, the participants that were considered to partake in the study were those who scored below $40 \%$ in the MKC. This process led to the selection of 8,7 and 9 participants across the three groups. Besides, the three schools were randomly assigned to the three groups namely gamification, experiential learning and control or traditional method group.

The second stage of the treatment involved the teaching of the participants based on the different instructional methods. The first and the second groups were exposed to gamification and experiential learning respectively as instructional intervention while the third group was used as the control group who were not exposed to the experiment. The period lasted for eight weeks and the topics in the test blueprint were taught using the respective instructional method for each group. In a week, lessons were taught four times with a contact of 50 minutes. A total of 200 minutes instruction was spent in a week for each group. In the gamification instructional intervention group, the participants were taught with ludo and 'snake and ladder' games.
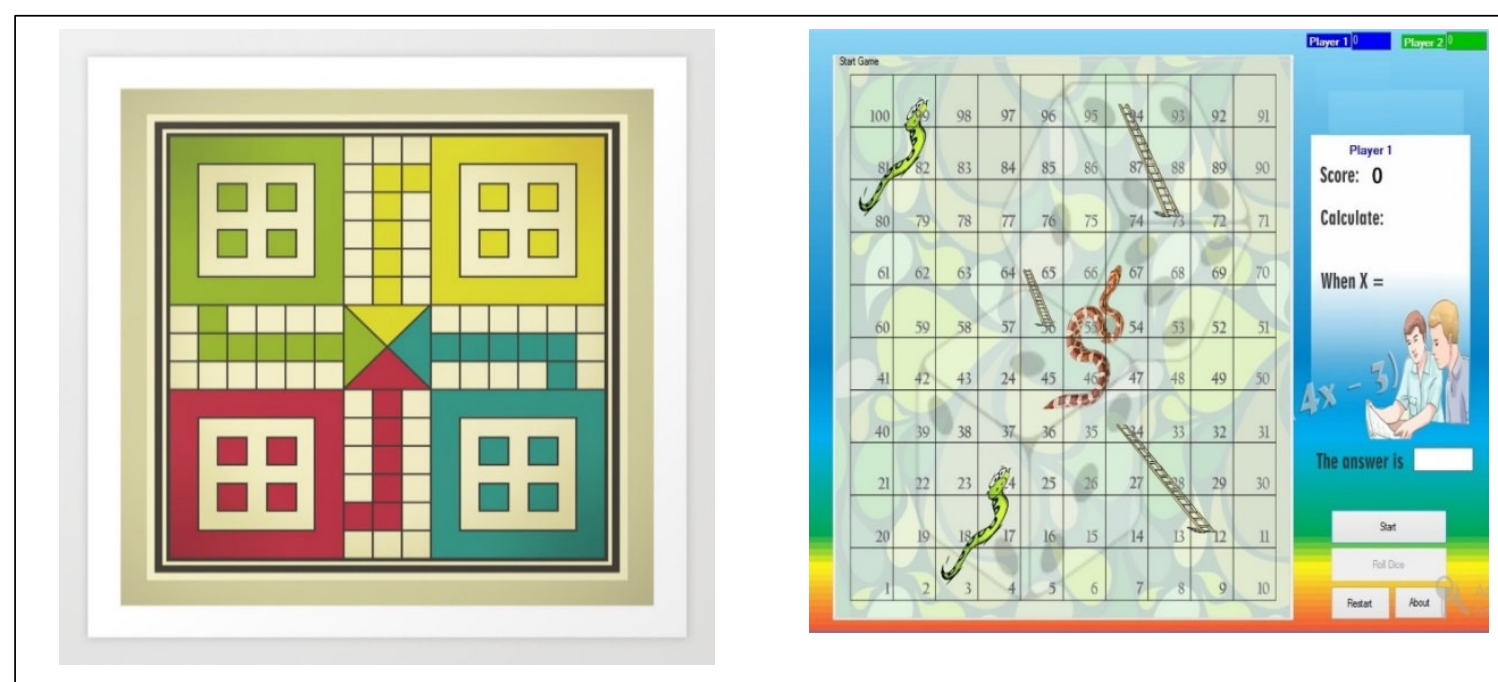

Figure 1 Ludo (left) and Snake \& Ladder (right) Games used during treatment 
Impact of gamification and experiential learning on achievement in mathematics among learners with hearing impairment in Lagos State, Nigeria

S. O. Adeniyi ${ }^{1}$ \& O. O. Kuku ${ }^{2}$

\section{Ludo dice game}

For measure of central tendency, mean and mode were taught. In the case of the mean, the dice was tossed up several times. The number achieved each time the dice went up was recorded. The total number of the times that the dice was tossed up was recorded. Addition of those numbers achieved when the dice tossed was dived the by number of times the dice was tossed. The average becomes the mean. The participants were also asked to do that until mastery is achieved.

For mode, the dice was tossed severally just like it happened when deriving the mean. The number achieved in each of the tosses was recorded. However, students were made to take note of the number that occur most frequently. The one identified as having the highest number of appearances was regarded as mode.

\section{Computerized snake and ladder game}

This was used to teach basic algebra basic operation (multiplication, addition and subtraction). The following steps were followed in playing the basic algebra computerized snake and ladder game:

Launch the game on the computer; Click on the start button of the game to activate the game; Click on roll the dice to display the dice rolled with an algebra problem, the number of the possible outcome of the dice is then substituted for the value expected in the algebra problem; The result then determines the movement of the player on the snake and ladder game board. As students achieve movement, they get motivated until they master the art solving basic algebra.

For experiential learning group, learners were actively engaged in the construction knowledge were taken through gathering of data in their class test, getting the frequency and computing the measure of central tendency from their observations. Basic algebra operations were also taught through their financial interactions/expenditures. The control group was not given a purposeful instructional strategy. Thus, the traditional method of teaching was used to teach the topics throughout the experiment.

The third stage of the experiment was in the eleventh week which involved the administration of MKC in order to measure the achievement of the learners in the different instructional groups. The scores collated at this stage were used for data analysis. The data collated were analyzed using descriptive statistical tools which include mean, standard deviation and mean difference. Besides, inferential statistics were used to test the significance of the postulated hypotheses. The hypotheses were tested at 0.05 level of significance and the analysis of covariance (ANCOVA) was used with the aid of the Statistical Package for Social Sciences (SPSS).

\section{Results}

Research Question 1: How does achievement in mathematics differ among participants exposed to gamification, experiential learning and traditional method group?

The pre-test and post-test results of the three groups (i.e., gamification, experiential learning, and traditional method) that participated in the study are presented in Table 3. 
African Journal of Educational Studies in Mathematics and Sciences Vol. 16, No. 2, 2020

Table 3 Results of the gamification, experiential learning and traditional method groups that participated in the pre-test and post-test

\begin{tabular}{lcccccc}
\hline & & \multicolumn{2}{c}{ Pretest } & \multicolumn{2}{c}{ Posttest } & \multirow{2}{*}{\begin{tabular}{c} 
Mean \\
\cline { 3 - 6 } Group
\end{tabular}} \\
\cline { 3 - 6 } & $\mathrm{N}$ & Mean & Std. Dev. & Mean & Std. Dev. & Difference \\
\hline Gamification & 8 & 14.50 & 5.29 & 27.13 & 6.20 & 12.63 \\
Experiential learning & 7 & 14.43 & 2.30 & 27.00 & 4.04 & 12.57 \\
Traditional method & 9 & 12.89 & 2.80 & 19.33 & 4.33 & 6.44 \\
Total & 24 & 13.88 & 3.64 & 24.17 & 6.09 & 10.29 \\
\hline
\end{tabular}

Observations from Table 3 show that the pretest achievement scores were 14.5, 14.43 and 12.89 for Gamification, Experiential learning and Traditional method Groups respectively. At Posttest, the mean achievement in Mathematics rose for the three groups and Gamification Group had 27.13, Experiential learning Group had 27 while Traditional method Group had 19.33. These imply the Gamification Group had the highest mean difference with 12.63 , followed by the Experiential learning Group with 12.57 while the Traditional method Group had 6.44.
Research Question 2: To what extent does achievement in mathematics differ among male and female participants exposed to the experimental conditions?

To ascertain if the differences in mean observed in Table 3 were statistically significant, the mean differences were further subjected to inferential analysis. Table 4. Shows the descriptive statistics of the results of the gamification, experiential learning and traditional method groups by gender.

The descriptive analysis in the pretest achievement scores for the male participants

Table 4 Descriptive statistics of the results of the gamification, experiential learning and traditional method groups by gender

\begin{tabular}{lllccccc}
\hline & & & \multicolumn{2}{c}{ Pretest } & \multicolumn{2}{c}{ Posttest } & \\
\cline { 3 - 6 } Group & Gender & $\mathrm{N}$ & Mean & $\begin{array}{c}\text { Std. } \\
\text { Deviation }\end{array}$ & Mean & $\begin{array}{c}\text { Std. } \\
\text { Deviation }\end{array}$ & $\begin{array}{c}\text { Mean } \\
\text { Difference }\end{array}$ \\
\hline Gamification & Male & 4 & 15.75 & 7.68 & 28.00 & 8.52 & 12.25 \\
& Female & 4 & 13.25 & 1.50 & 26.25 & 3.86 & 13.00 \\
& Total & 8 & 14.50 & 5.29 & 27.13 & 6.20 & 12.63 \\
Experiential & Male & 3 & 15.67 & 2.31 & 29.33 & 5.03 & 13.67 \\
learning & Female & 4 & 13.50 & 2.08 & 25.25 & 2.50 & 11.75 \\
& Total & 7 & 14.43 & 2.30 & 27.00 & 4.04 & 12.57 \\
Traditional & Male & 3 & 13.33 & 4.73 & 18.00 & 7.21 & 4.67 \\
method & Female & 6 & 12.67 & 1.86 & 20.00 & 2.76 & 7.33 \\
& Total & 9 & 12.89 & 2.80 & 19.33 & 4.33 & 6.44 \\
Total & Male & 10 & 15.00 & 5.21 & 25.40 & 8.24 & 10.40 \\
& Female & 14 & 13.07 & 1.73 & 23.29 & 4.08 & 10.21 \\
& Total & 24 & 13.88 & 3.64 & 24.17 & 6.09 & 10.29 \\
\hline
\end{tabular}


Impact of gamification and experiential learning on achievement in mathematics among learners with hearing impairment in Lagos State, Nigeria

S. O. Adeniyi $i^{1} \&$ O. O. Kuku ${ }^{2}$

showed that gamification, experiential learning and traditional method group had $15.75, \quad 15.67$ and 13.33 respectively. Besides, the female participants had 13.25 for gamification group, 13.50 for experiential learning group and 12.67 for the traditional method group.

The male posttest achievement mean scores for gamification rose to 28, while for experiential learning and traditional method groups, the mean score rose to 29.33 and 18 respectively. The female counterparts also witnessed increase in their mean achievement scores across the experimental groups with gamification, experiential learning and traditional method groups having $26.25,25.25$ and 20 respectively.
A further analysis was carried using the oneway Analysis of Variance (ANOVA) to test the null hypothesis that achievement in mathematics will not significantly differ among participants exposed to gamification, experiential learning and traditional method group and the result is presented in Table 5.

Result from Table 5 showed that 9.562 was derived as the F-calculated value of mean achievement across the experimental groups. The F-calculated $(9.562 ; \mathrm{p}=0.001)$ was found to be greater than the critical value of 3.49 given degrees of freedom 2 and 20 , at 0.05 level of significance. Consequently, the null hypothesis was rejected and it was concluded that achievement in Mathematics significantly

Table 5 One-way Analysis of Variance (ANOVA) of the scores of the gamification, experiential learning and traditional method groups by gender

\begin{tabular}{lrrrrr}
\hline Source & Sum of Squares & Df & Mean Square & \multicolumn{1}{c}{ F } & \multicolumn{1}{c}{ Sig. } \\
\hline Corrected Model & 643.755 & 3 & 214.585 & 20.478 & .000 \\
Intercept & 145.018 & 1 & 145.018 & 13.839 & .001 \\
Covariate & 307.297 & 1 & 307.297 & 29.325 & .000 \\
Group & 200.402 & 2 & 100.201 & 9.562 & .001 \\
Error & 209.578 & 20 & 10.479 & & \\
Total & 14870.000 & 24 & & & \\
Corrected Total & 853.333 & 23 & & & \\
\hline
\end{tabular}

Assessing the mean differences for male participants across the experimental groups shows that the experiential learning group had the highest with 13.67, followed by gamification group with 12.25 and the traditional method with 4.67. similarly, the mean differences for female participants across the experimental groups shows that the gamification group had the highest with 13, followed by experiential learning group with 11.75 and the traditional method with 7.33 . differ among students exposed to gamification, experiential learning and traditional method group. 
African Journal of Educational Studies in Mathematics and Sciences Vol. 16, No. 2, 2020

A further analysis was used to determine the pair that was found to be significant using multiple comparisons, Least Significance achievement when compared to the traditional method group.

Finally, to determine the effect of gender, a

Table 6 Multiple comparison analysis of mean achievement across groups

\begin{tabular}{llcc}
\hline (I) Group & (J) Group & Mean Difference (I-J) & Sig. $^{\text {b }}$ \\
\hline Gamification & Experiential learning & .052 & .976 \\
& Traditional method & $6.135^{*}$ & .001 \\
Experiential learning & Gamification & -.052 & .976 \\
& Traditional method & $6.083^{*}$ & .002 \\
Traditional method & Gamification & $-6.135^{*}$ & .001 \\
& Experiential learning & $-6.083^{*}$ & .002 \\
\hline
\end{tabular}

Based on estimated marginal means

*. The mean difference is significant at the .05 level.

b. Adjustment for multiple comparisons: Least Significant Difference (equivalent to no adjustments).

Difference (LSD) method. Table 6 displays the result of the posthoc analysis.

Result of LSD analysis showed that the pairwise comparison of traditional method group and gamification group $(\mathrm{t}=6.135 ; \mathrm{p}=$ 0.001 ) as well as traditional method group and Experiential learning group $(\mathrm{t}=6.083 ; \mathrm{p}$ $=0.002$ ) were significant. However, the pairwise comparison of gamification and experiential learning group were not significant $(t=0.052 ; p=0.976)$. This shows that both gamification group and experiential learning group were effective in the improvement of learners' mean further analysis by (ANCOVA) was done to test the null hypothesis that 'there is no significant difference in achievement in mathematics as a result exposing participant to the experimental conditions due to gender'. Table 7 displays the results.

The result of the analysis in Table 7 shows that a F-calculated value of 0.857 was found as the achievement in mathematics as a result exposing respondents to the experimental conditions due to gender. The value observed to be less that the critical value of 3.47 given 2 and 17 degrees of freedom at 0.05 level of significance. As a

Table 7 Analysis of Covariance (ANCOVA) of the scores of the gamification, experiential learning and traditional method groups by gender

\begin{tabular}{lrrrrr}
\hline Source & Sum of Squares & df & Mean Square & \multicolumn{1}{c}{ F } & Sig. \\
\hline Corrected Model & 665.430 & 6 & 110.905 & 10.034 & .000 \\
Intercept & 129.174 & 1 & 129.174 & 11.687 & .003 \\
Covariate & 286.263 & 1 & 286.263 & 25.899 & .000 \\
Group & 217.632 & 2 & 108.816 & 9.845 & .001 \\
Gender & 1.645 & 1 & 1.645 & .149 & .704 \\
Group * Gender & 18.939 & 2 & 9.469 & .857 & .442 \\
Error & 187.903 & 17 & 11.053 & & \\
Total & 14870.000 & 24 & & & \\
Corrected Total & 853.333 & 23 & & & \\
\hline
\end{tabular}


Impact of gamification and experiential learning on achievement in mathematics among learners with hearing impairment in Lagos State, Nigeria

S. O. Adeniyi ${ }^{1}$ \& O. O. Kuku ${ }^{2}$

result, the null hypothesis was upheld and it was concluded that there is no significant difference in mathematics achievement as a result exposing respondents to the experimental conditions due to gender.

\section{Discussion of Findings}

The findings of this study revealed that achievement in mathematics differ as a result of exposing learners with hearing impairment to the interventions. The gamification group and experiential learning group were effective in the improvement of learners with hearing impairment mathematics achievement when compared to the traditional method group. This would be as a result of the ways the interventions have impacted on the learners' academic activities. An active classroom participation, effective learners-teachers interaction and dynamism ware observed in the learners' learning processes. However, achievement of learners with hearing impairment in gamification group was found to be marginally better than their counterpart in experiential learning group. This finding is in tandem with the submission of Tanridiler, Uzuner \& Girgin (2015) that use of such as participating balanced mathematics instruction (BMI) would benefit hearingimpaired students during mathematics classroom instructions. Also, the results also corroborated Marinagi and Skourlas (2013) that used web-based game activities that integrate wireless networks and mobile devices into educational scenarios. The result revealed that there was increase interest in daily studies and improves communications between learners and teachers. Furthermore, the results of the study were also in line with Parvez, et al. (2019) that conducted a study that require technology-based intervention to enhance teaching mathematical concepts using Pakistan Sign Language (PSL). The researchers reported that Experimental learning Group participants, who were instructed by our mobile application, showed higher proficiency in the quizzes as compared to the Traditional method Group. In addition, Experimental learning participants performed better than Traditional method Group by $12 \%$ in the quizzes.

It was observed that male and female learners with hearing impairment achievement in mathematics do not differ as a result of the experimental condition. This finding aligns with the observation of Adeniyi and Kuku (2018) who reported no significant difference in the reasoning ability of male and female children with hearing impairment as a result of introducing two instructional methods. Also, Appiah (2015) reported that there was no difference in the performance of male and female participants as a result of using gamification strategy to improve mathematics of pupils. However, this finding varied with the observation of Parvez, et al. (2019) while using technologybased intervention to enhance teaching mathematics concepts. It was reported that there was gender-based difference in quiz scores. The researcher observed that male participants in the experimental group performed better than their female counterpart despite both genders completing the quizzes. However, the non-significant gender difference could be adduced to the fact that both male and female students with hearing impairment have similar confounding conditions and will benefit in the same way. Hence, the positive impact of the two interventions strategies is a welcome development and would a new innovation in the education and learning process of students with hearing impairment. 
African Journal of Educational Studies in Mathematics and Sciences Vol. 16, No. 2, 2020

\section{Conclusion}

This study investigated the impact of gamification and experiential learning strategies on achievement in mathematics among students with hearing impairment in Lagos State, Nigeria. The results demonstrated positive impact of the two intervention strategies on the participants with gamification instructional method having higher impact on the achievement in mathematics among learners. The results further revealed no significant gender implication in the two intervention strategies pointing to the fact the two interventions benefit both male and female students with hearing impairment in the same way.

\section{Limitation of the Study}

The study was constrained by paucity fund because it was self-sponsored, which is the reason why it cannot go beyond Lagos State and the results of the study can only be generalized among the hearing impaired within Lagos State.

\section{Recommendations}

The result of the study shows that both gamification and experiential learning strategies can be adopted among learners with hearing impairment during mathematics lessons. The gamification learning strategies could be used ahead experiential learning strategies because it has better impact on the achievement of learners with hearing impairment. In addition, gender of the learners with hearing impairment should not be considered in planning intervention involving gamification and experiential learning strategies in mathematics.

\section{References}

Adeniyi, S. O., \& Kuku, O. O. (2018). Effectiveness of two instructional methods on reasoning ability of children with hearing impairment in
Nigeria. Specijalnaedukacija $i$ rehabilitacija, 17(4), 395-417. https://doi.org/10.5937/specedreh17 -18600 .

Appiah, D. B. (2015). Gamification in education: Improving elementary mathematics through engagement in hybrid learning in the classroom. Master Thesis, Department of General Art Studies, Kwame Nkrumah University of Science and Technology, Ghana.

Arora, R. (2016). Academic achievement of adolescents in relation to study habits. The International Journal of Indian Psychology, 3(2), 47-54.

Ashmore, B. (2017). A study of the performance of deaf/hard of hearing students in high school mathematics on conceptual understanding, procedural fluency, and mathematical reasoning tasks. Master Thesis, The College at Brockport, State University of New York. Retrieved from 896. https://digitalcommons.brockport.ed u/ehd_theses/896

Banfield, J., \& Wilkerson, B. (2014). Increasing student intrinsic motivation and self-efficacy through gamification pedagogy. Contemporary Issues in Education Research, 7(4), 291-298.

Boyle, E. A., Hainey, T., Connolly, T. M., Gray, G., Earp, J., Ott, M., . . . Pereira, J. (2016). An update to the systematic literature review of empirical evidence of the impacts and outcomes of computer games and serious games. Computers \& Education, 94, 178-192. https://doi.org/10.1016/j.compedu.2 015.11 .003 
Impact of gamification and experiential learning on achievement in mathematics among learners with hearing impairment in Lagos State, Nigeria

Caemmerer, J. J., Cawthon, S. W., \& Bond, M. (2016). Comparison of students' achievement: Deaf, learning disabled, and deaf with a learning disability. School Psychology Review, 45(3), 362-371.

Canadian Council on Learning (2009). The Impact of Experiential Learning Programs on Student Success.

Cohen, S. J. (2016). Investigating the impact of gamification on student performance in a secondary science classroom. Master Thesis, Department of Science Education, Montana State University

Gafni, R., Achituv, D. B., Eidelman, S., \& Chatsky, T. (2018). The effects of gamification elements in e-learning platforms. Online Journal of Applied Knowledge Management, 6(2), 3753

Gottardis, L., Nunes, T., \& Lunt, I. (2011). A synthesis of research on deaf and hearing children's mathematical achievement. Deafness and Education International, 13(3), 131150.

Hainey, T., Connolly, T. B., Azadegan, A. W., Amanda, R. A., \& Gray, G. (2014). A systematic literature review to identify empirical evidence on the use of games-based learning in primary education for knowledge acquisition and content understanding. Proceedings of the European Conference on Games Based Learning, 1, 167-175

Jagoda, P. (2013). Gamification and other forms of play. Boundary, 40(2), 113144.
S. O. Adeniyi ${ }^{1} \&$ O. O. Kuku ${ }^{2}$ https://doi.org/10.1215/019036592151821

Kuku, O. O. (2019). Effectiveness of frequency of testing on students' study habits in mathematics among senior secondary school students in Ogun State, Nigeria. UNILAG Journal of Humanities, 7(2), 179192.

Marinagi, C., \& Skourlas, C. (2013). Blended learning in personalized assistive learning environments. International Journal of Mobile and Blended Learning, 5(2), 39-59. https://doi.org/10.4018/jmbl.201304 0103

Nath, S. (2016). Instructional Programme on experiential learning in science education: Appraising its impact through students' reflections. Literacy Information and Computer Education Journal (LICEJ), 7(1), 2238-2247.

National Council of Teachers of Mathematics. (2000). Principles and standards for school mathematics. VA: NCTM Reston.

Noorian, M., Maleki, S. A., \& Abolhassani, M. (2013). Comparing of mathematical students of deaf and normal types. International Research Journal of Applied and Basic Sciences, 7(6), 367-370.

Nunes, T., \& Moreno, C. (2002). An intervention program for promoting deaf pupils' achievement in mathematics. Journal of Deaf Studies and Deaf Education, 7(2), 120-133.

Pagliaro, C. M., \& Kritzer, K. L. (2005). Discrete mathematics in deaf 
African Journal of Educational Studies in Mathematics and Sciences Vol. 16, No. 2, 2020

education: A survey of teachers' knowledge and uses. American Annals of the Deaf, 150(3), 251-259.

Parvez, K., Khan, M., Iqbal, J., Tahir, M., Alghamdi, A., Alqarni, M., Alzaidi, A. A., \& Javaid, N. (2019). Measuring Effectiveness of Mobile Application in Learning Basic Mathematical Concepts Using Sign Language. Sustainability, 11, 1-20. https://doi.org/10.3390/su11113064

Shelton, B. E., \& Parlin, M. A. (2016). Teaching Math to Deaf/Hard-ofHearing (DHH) Children Using Mobile Games: Outcomes with Student and Teacher Perspectives. International Journal of Mobile and Blended Learning, 8(1), 1-17. https://doi.org/10.4018/IJMBL.2016 010101

Sylvia, M. (2015).Factors contributing to low achievement levels in mathematics among hearing impaired learners: A case of selected schools of Lusaka, Zambia. Master Dissertation, The University of Zambia, Lusaka
Tanridiler, A., Uzuner, T., \& Girgin, U. (2015). Teaching and Learning Mathematics with Hearing Impaired Students. Anthropologist, 22(2), 237-248.

Taspinar, B., Schmidt, W., \& Schuhbauer, H. (2016). Gamification in education: A board game approach to knowledge acquisition. Procedia Computer Science, 99, 101-116. https://doi.org/10.1016/j.procs.2016. 09.104

Türkmen, G. P., \& Soybaş, D. (2019). The effect of gamification methodology on students' achievements and attitudes towards mathematics. Bartın University Journal of Faculty of Education, 8(1), 258-298. https://doi.org/10.14686/buefad.424 575

Wynn, A. H. (2018). The effect of experiential learning on mathematics achievement and mathematics anxiety of AfricanAmerican students. Doctoral Dissertation, Liberty University 

African Journal of Educational Studies in Mathematics and Sciences Vol. 16, No. 2, 2020

Open Access article distributed under the terms of the Creative Commons Attributions License [CC BY-NC-ND 4.0] http://creativecommons.org/licenses/by-nc-nd/4.0. DOI: https://dx.doi.org/10.4314/ajesms.v16i.2.4 